\title{
Dai dwellings elasto-plastic analysis on seismic performance of steel - wood structures
}

\section{LIU Dewen ${ }^{\text {a }, ~ L I ~ J i n g, ~ X I A ~ B i n g h u a, ~ L I A O ~ W e n y u a n, ~ W A N G ~ C h e n x i n g, ~}$ JIANG Shujiang, LIU Chang, CAI Yurong, XU Min}

College of Civil Engineering, Southwest Forestry University, Kunming, China

aemail:350376315@qq.com

Keywords: steel-wood- plastic; Dai dwellings; seismic performance

\begin{abstract}
The light steel-wood- plastic structure of the Dai national folk houses combines the development history of Dai buildings and national culture, which is a new structure suddenly rised. This structure not only meets the local living requirements, but also is one green building.Besides, the structure is conducive to protect the natural environment and plays an important role in building a well-off society in an all-round way. This paper studies the engineering examples, analyzing the anti - seismic elasto - plasticity of the built Dai houses and providing some theoretical basis and reasonable suggestions for this new structure.
\end{abstract}

At present, China is in the stage of economic transformation, cultural prosperity and industrial structure adjustment, and rural development in China has entered a new stage. The time for building a new socialist countryside is becoming more and more mature, and the country is vigorously developing green building and socialist new rural construction. As the response to the call of the party and state, in recent years, yunnan provincial party committee, provincial government increased the support for new rural construction, seriously implement the general secretary of yunnan's important speech, xi proposed accelerate the dangerous house renovation and earthquake-resistant housing projects in yunnan province. Yunnan province is a multi-ethnic region to protect the local ethnic architecture and cultural characteristics, protect the local natural environment, and realize the green construction. In recent years, yunnan province has vigorously promoted the construction of light steel-wood plastic structures. Currently in yunnan xishuangbanna, zhaotong, chuxiong, yuxi and other places all have light steel - wood-plastic housing. Of zhaotong, chuxiong, etc in light steel and brick wall, light steel and brick, wood plastic composite structures, and xishuangbanna dai national minority region out of respect for material, water, environment, local dai dwellings as light steel and wood structure. At present, a large number of steel - 
wood-plastic structures have been put into use, and there are many houses under construction. To explore light steel and wood plastic structure whether meet the requirements of the local seismic let common people live at ease, rest assured, we will speed up the establishment of a new socialist countryside, to complete the task of the rural poor out of poverty.

The lower heavy steel structure is adopted in the dai houses, and the thin-walled light steel structure of the upper part is cold. In the early stage of the project, the standard is not unified, many revisions, the theoretical research of the plan is not clear. This new type of structure belongs to the exploration stage, and the theoretical knowledge of the seismic performance of the structure is badly needed. Although the seismic research of light steel structure at home and abroad is relatively mature, but chongqing steel and light steel, wood and plastic this kind of composite structure is still a lack of relevant aseismic theory analysis and experiment research, chongqing steel and light steel transformation layer between the seismic performance, wood plastic structure on the influence of the steel structure of main body, optimization of assembly, etc., this research is less at present academia and engineering. In nonlinear analysis, the structural analysis of fully considering all the important nonlinear factors, thus the structure of the actual failure mode can be integrated and comprehensive assessment, and the ultimate bearing capacity of structure of direct access to the whole. The purpose of nonlinear analysis is to apply it to higher design. In this way, the concept of calculating length of component and the related equation of component strength can be abandoned in the structure design, so that the design process can be simplified radically. The overall seismic elastic plasticity of steel - wood plastic structure can provide theoretical and design basis for this project.

Dai light steel and wood plastic residential green environmental protection, economical and practical, on the seismic elastic and elastoplastic analysis, complete relevant theoretical basis, is conducive to the further development of this new type of structure and promotion. In the face of the multiple earthquakes in yunnan, the conditions of high winds and heavy rainfall, the numerical modeling of light steel and wood plastic structures was carried out through different software, and the data were compared and analyzed, and the seismic weak points were obtained and improved. The seismic performance of the upper and lower part of the conversion layer and the seismic 
performance of the whole are further studied, and the lower structure system of the lower structure is tried to improve or redesign the lower heavy steel section of the structure. Is beneficial to reduce the use amount of the actual project of sinosteel, reduce the project cost, optimize the structure of the seismic stability, improve the use fixed number of year, develop a reasonable assembly components to reduce installation time, etc., promote the industrialization of China's steel and wood plastic local-style dwelling houses building.

Seismicity in yunnan province as the plate and plate edge features, unique natural geographical position, make the frequency of the earthquake in the region is on the high side, the intensity is big, the source has a wide distribution and shallow, the earthquake type is relatively abundant, such as earthquake, isolated bi-directional earthquake type earthquake, the main quake aftershock compound etc., this is the strongest regional - contributed to China's earthquake activity in yunnan. Since recorded history, almost all of the province's 128 counties and cities suffered intensity VI degrees above the destruction of the earthquake, which occurred more than 5 [1] is more than 110 counties, experienced over magnitude 7 earthquake more than 10 counties. From 1992 to 2014, more than 90 earthquakes occurred in yunnan province. The devastating earthquake in 2014 alone caused an economic loss of 336.13.1 billion yuan. Today, the devastating earthquake will cause more and more serious economic or property losses. Then it is necessary to study the new structure of yunnan dai nationality light steel - wood plastic (new rural characteristic residential).

Xishuangbanna belongs to the tropical humid climate. The area of rubber trees planted in the area is larger, producing a large amount of rubber seeds. HuaKun biotechnology company, using the domestic and foreign advanced technology to redefine rubber seed and rubber wood, make the land waste, waste not only can produce the traditional rubber seed oil, and can use the remaining material adding auxiliary materials to produce new wood plastic composite (figure 1). If the dai ethnic group is developed vigorously, it will not only improve the living environment of the people, but also promote the development of local economy and raise the incomes of the people, and form a unique economic industrial chain. 

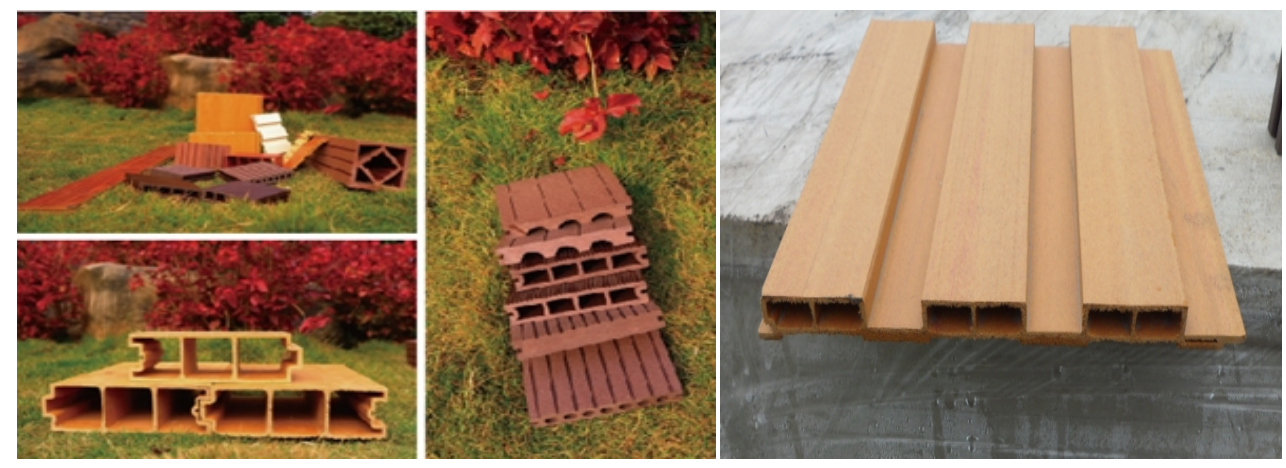

Fig1 Various models Wood Plastic Composite

\section{Acknowledgements}

This work was financially supported by Yunnan Science and Technology Department Fund Project (2016RA079) ; Yunnan Provincial Department of Education Fund Project（2015Y298)

\section{Reference}

[1] Roeder Charles W, Popov E P. Eccentrically Braced Steel Frames for Earthquakes[J]. Journal of the Structural Division, Vol.104, No. 3, March 1978:391-412.

[2] Hjelmstad K D, Popov E P. Characteristics of Eccentrically Brace Frames[J].Journal of Structu-ral Engineering, 1984(2):340-353.

[3] Jain Ashok K, Goel S C. Seismic Response of Eccentrically Braced Frames[J].Journal of The Structural Division, $1980(4): 843-860$. 